The Geneva Papers on Risk and Insurance, 23 (No. 89, October 1998), 496-499

\title{
Emerging Regions and Insurance: a Reflection on Latin-American Markets
}

by Filomeno Mira*

\section{The region}

Latin-America is a huge territory of more than 20 million square $\mathrm{km}, 19$ countries and near to 500 million inhabitants, where the mix of Indian and European cultures (mainly Spanish and Portuguese) has produced a rather strong common identity - very close to Western forms - despite the local differences and rivalries.

In the last ten to twenty years, significant political and economic changes have been steadily introduced in practically all countries, driving the region into a relatively stable market where economic and social growth are more and more a reality. The establishment of democratic regimes and the enforcement of strict macroeconomic and social legislation are responsible for those advances; although poverty, political corruption and social injustice are still issues which demand improvement.

Economic reforms have been focused on the opening of the commercial markets, reducing the activity of public sector, and introducing new legislation for deregulation and liberalization. Dollarization of some economies is a factor which in some way is responsible for a certain stabilization.

At the same time, old inter-regional markets have been promoted (Pacto Andino, Mercado Común Centroamericano, Grupo de los Tres) and new ones (Mercosur mainly) have been created in an attempt to give an international drive to these political and economic forces. This movement is today orientated toward new economic links with other regional markets, specially the EU, USA and Canada (in this case, through the

* Vice-Chairman, Corporation MAPFRE, Madrid, Spain. 
NAFTA agreement). With all this, regional trade has received a never before known push and dynamism.

To give some figures, in 1997 the average GDP increase was $5.3 \%$, and the inflation rate was below $11 \%$. Investment rates grew even more than GDP, due to the inflow of foreign capital ( 73 billion US \$), bigger in any case than the foreign deficit. External debt reached 644 billion US \$, showing a $2.5 \%$ increase.

In the short and medium term, the Latin-American economy can be affected by international crisis (as happened to some extent at the end of ' 97 with the Asian financial turmoil) or local circumstances (new reforms are still necessary, mainly for reducing public spending, opening financial structures and creating a more flexible labour market), but in the long run there is no doubt a high potential for economic development in the region, as is underlined by the IDB (Inter-American Development Bank) and other international institutions. The USA and the EU are also showing a growing interest in Latin-America. The former trying to promote a whole new Free Trade Area (ALCA, or Area de Libre Comercio de las Américas), and the latter looking for special alliances. Perhaps both are intending to improve their positions and influence in those countries as a battle field for the upcoming euro-dollar fight. Probably the dollar, well rooted in Latin-America, will prevail for those economies, but in the long run both could co-exist side by side.

\section{The insurance market}

In the past, it was not easy to find references to Latin-America as a whole in the insurance sector, despite the increasing efforts of FIDES (Federación Interamericana de Empresas de Seguros) and other international institutions. Nowadays more and more statistics and data are provided as globalization and interregional trade progress and demand more information. In 1996, the premium income of the region reached 32 billion US $\$, 1.8 \%$ of GDP, with only $28 \%$ in life insurance. That meant only $1.5 \%$ of insurance premium income world-wide, though some years before that this figure was a mere $1.0 \%$. The growth and development trends point toward near to $2.0 \%$ of the world insurance market.

The big giant of the region, Brazil, is responsible for $50 \%$ of the above figures, but small countries have a strong potential and dynamism, with very interesting niches to tap into.

In general, the main features of the Latin-American insurance market could be briefly summarised as follows:

- Economic growth, reduction of inflation rates and the social security reforms have significantly increased the demand for insurance products. Still, insurance uptake is very low, with a meagre 70 US $\$$ per capita ratio.

- Deregulation and foreign new-comers have promoted efficiency and competition with cut-throat tariffs, though governmental taxes and low productivity are hindering development.

- Life and related insurances (pension schemes, health, annuities ...) are going to have a tremendous development in the near future after the new legislation concerning the privatizacion of social securities has been enforced, following the positive Chilean 
experience. Banks are going to be important players in this field, either acting alone or in alliance with local insurers. A big investment from European banks (mainly from Spain) made in the last few years in most countries could be the beginning of that commercial-war.

- Motor insurance, the leading line in practically all markets, is going to undergo an important transformation due to new legislations, (enforcing it as a compulsory insurance) and more efficient techniques to manage it as a mass product to obtain customers for other business lines.

- Exposure to catastrophic perils (earthquakes, hurricanes and climate changes, due in part to the El Niño phenomenon) and social unrest and violence (drugs running and guerrilla activity, mainly) will require special covers and protections, where international reinsurers must play a key role, preferably with the collaboration of local governmental institutions which should be urgently promoted.

- More deregulation should be accomplished with the elimination of still existing monopolies and restrictions to free competition or foreign investors (in insurance and reinsurance) and easing tariffs and wording controls.

- Legislation on solvency margins and capital requirements is changing in most countries toward international parameters, following regular European standards. The Association of Insurance Commissioners (ASSAL) is improving relations between countries and driving the region towards a common market with similar rules.

- Nevertheless, stricter supervision should be instituted on solvency margins and investment risks, instead of bureaucratic control of operating issues.

Foreign insurance groups have historically been present in Latin-America, but have not been very active in the last few decades, until recently when there has been a repositioning in the markets as globalization and deregulation prompted a strategic reaction. So, today European and North American groups directly share at least $30 \%$ of that market (15\% each approximately) with a strong increase in the last years, especially for the U.S. companies. The financial crisis and legal difficulties in other emerging regions (China, India, South East Asia) has helped this movement which probably will be enhanced in the near future due to the characteristics of this region which were mentioned earlier.

\section{Some final reflections}

In spite of the distances and local differences, Latin-American countries can be considered as having a common market for economic and insurance purposes, due to their similar culture and legislation, which ease inter-regional trade and globalization.

The richness and human potential, close to Western culture, will favor a strong development of economic growth and insurance and financial activities in the near future. The USA and the EU will play an important role, even in competition, to share this emerging market with local institutions and companies.

New areas and niches will require special techniques or expertise, both in management and technology, and this is a difficult task only possible for international 
organisations and big local companies. The insurance operation requires a lot of time to adapt old organizations and correct defects and bad habits. Transforming the habits of customers and employees is neither easy nor fast, but the companies which are able to do so will have a significant advantage and take the lead in this race.

Mass Insurance products (property, health, motor, pension schemes, etc) will have a huge development, and for that, insurance companies' efficiency must improve dramatically. Commercial lines require good international brokerage firms which are established or net-linked in all countries, where industrial foreign investment is reaching a level never before known, and global solutions are usually required.

The Geneva Association has devoted time and has favoured discussions in its 25 years of history to concerns related to Latin-America: its development, insurability of catastrophic risks, health and pension systems after the Chilean experience, amongst others. My personal feeling is that more analysis should be done in the future from a research point of view, and as a matter of concern to most of its members because of most of the reasons mentioned in this article.

Perhaps one issue of increasing interest could be that more local leadership is needed in some countries, and indeed in the whole region, giving a major role to the local players and new investors, who should be more aware of the possibilities of their markets. Joining forces with international groups could be a driving force to promote a fast and tremendous development in those insurance markets in favor of social development, which is, without any doubt, the main reason for insurance. 